\title{
Anthós
}

6-2009

\section{Cultural Responses to Climate Change in the Holocene}

Richard Prentice

Portland State University

Follow this and additional works at: https://pdxscholar.library.pdx.edu/anthos

Part of the Agriculture Commons, Archaeological Anthropology Commons, and the Cultural History Commons

Let us know how access to this document benefits you.

\section{Recommended Citation}

Prentice, Richard (2009) "Cultural Responses to Climate Change in the Holocene," Anthós: Vol. 1: Iss. 1, Article 3.

https://doi.org/10.15760/anthos.2009.41

This open access Article is distributed under the terms of the Creative Commons Attribution-NonCommercialShareAlike 4.0 International License (CC BY-NC-SA 4.0). All documents in PDXScholar should meet accessibility standards. If we can make this document more accessible to you, contact our team. 


\title{
CULTURAL RESPONSES TO CLIMATE CHANGE IN THE HOLOCENE
}

\author{
Richard Prentice \\ Portland State University
}




\author{
Richard Prentice \\ Portland State University
}

\begin{abstract}
Variable Holocene climate conditions have caused cultures to thrive, adapt or fail. The invention of agriculture and the domestication of plants and animals allowed sedentary societies to develop and are the result of the climate becoming warmer after the last glaciation. The subsequent cooling of the Younger Dryas forced humans to concentrate into geographic areas that had an abundant water supply and ultimately favorable conditions for the use of agriculture and widespread domestication of plants and animals. Population densities would have reached a threshold and forced a return to foraging, however the end of the Younger Dryas at 10,000 BP allowed agrarian societies to grow in number and expand spatially. The Norse took advantage of the favorable climate conditions of the medieval warm period $(800$ to $1300 \mathrm{CE}$ ) to establish settlements off the coast of Greenland, but the onset of the Little Ice Age (1350-1850 CE) caused sea ice to block trade routes with China and led to their demise. The long and cold winters of the Little Ice Age inspired works of art and literature, and were celebrated in London, but also caused crop failures, famine and disease. The Dust Bowl drought of the 1930's only lasted six years but caused the most devastating ecological, sociological, agricultural, and economic disaster in United States history. Multicentury and multidecadal droughts led to the collapse of the Akkadian, Classic Maya, Mochica, and Tiwanaku civilizations. The primary factors affecting global climate variations include changes in thermohaline circulation, solar irradiance, and the effects of active volcanoes. Complex societies are not completely powerless nor fully adaptive to climate change. Modern society should use knowledge of past abrupt climate changes to better prepare for the future.
\end{abstract}

Culture has been directly affected by abrupt climate change throughout the geological record (Gupta, 2004). Humans adapted and migrated in response to severe, repeated, abrupt climate changes. Archaeological findings show that humans adapted to the extreme cold climate of the Arctic during the late Pleistocene about 27,000 years ago. They adapted to arid conditions in the Thar and Sahara Deserts in the late Holocene. Some civilizations have collapsed as a result of climate change. The Akkadian, Classic Maya, Mochica and Tiwanaku civilizations disbanded because of related persistent multicentury climate change. Civililizations in South Asia have also been altered due to climate change.

\title{
The Origin of Agriculture
}

The first Humans were hunters and gatherers who subsisted on natural vegetation and game (Dow, 2005). They did not establish permanent settlements, relocating when the seasons or climate changed. Agriculture did not start during the Pleistocene because the cold, glacial climate was not favorable to it. Richardson (2001) argues that agriculture was impossible in the Pleistocene ice age because the climate was extremely cold and dry, containing higher levels of carbon dioxide, and varied greatly sometimes in periods of a decade or less. Between the years 10,000- 7000 BP (the start of the Holocene), the climate became warmer, causing vegetation to increase and shift from one type to another. People adapted to this by changing the foods they ate and altering their lifestyle. Many people began to domesticate plants and animals at this time, both as a direct and indirect response to climate change, thus the origin of agriculture.

The domestication of plants and animals began in Asia, then independently through north China, South China, sub-Saharan Africa, Mexico, the Andes, and eastern North America. Dogs were domesticated first, followed by goats and sheep. Dogs were used to assist in hunting, and goats and sheep provided milk, wool and meat. The bones 
of goats and sheep found at human encampments show the animals were more varied in age after the start of the Holocene, and outside of where they would normally live. This is evidence that humans were herding the animals. Throughout the Holocene plants and animals were domesticated all over the world. This also includes, but is not limited to cabbage, wheat, barley, horses, lentils, peas, pigs, and cattle. The herders engaged in pastoral nomadicism, moving with the herds along seasonal grazing areas.

Domestication started in the tropics and subtropics of southwest Asia at end of the last glacial maximum because the wet, warm climate made growing conditions ideal (Gupta 2004). The Fertile Crescent starts at the Tigris and Euphrates rivers and extends north to eastern Turkey, then south to the coasts of Lebanon and Israel (Fig. 1).

Archeological sites along this crescent reveal evidence of the earliest plant domestication. Humans were aware of the increased vegetation and were naturally curious about it. They experimented with it, discovered different ways to use it, and built stone and metal tools to farm with. These tools were used to clear the land and aid in crop production, but also helped domesticate plants and animals. Larger animals were used to pull farm tools.

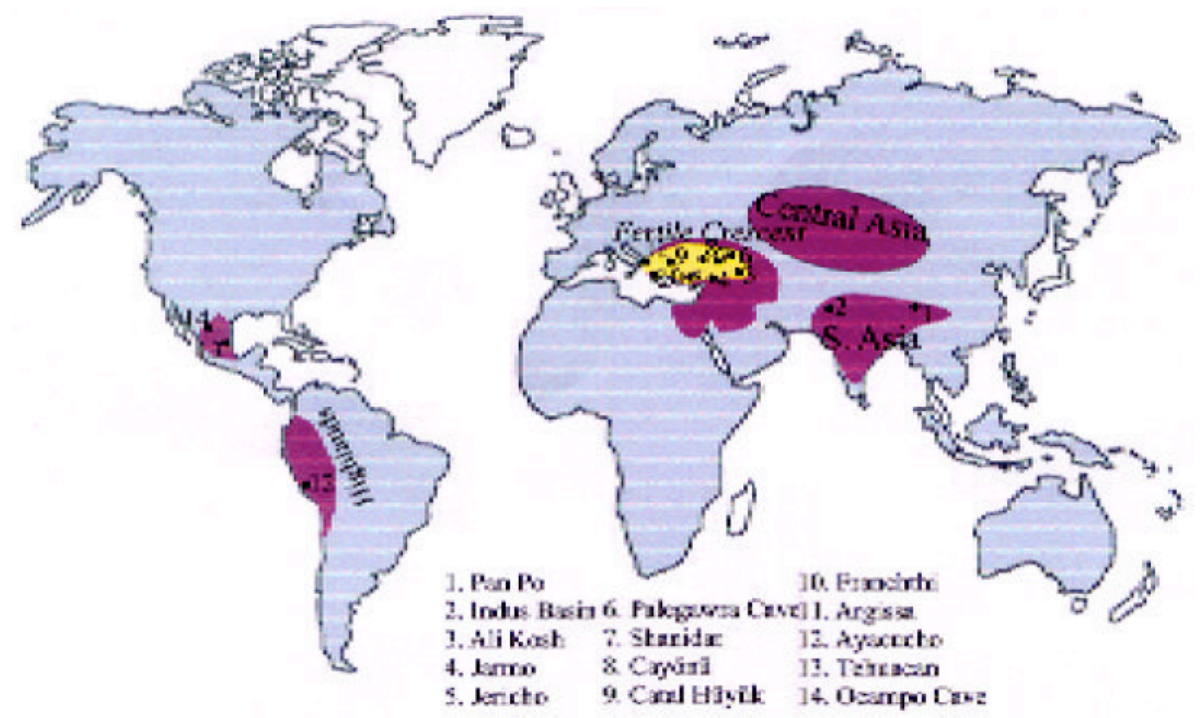

Figure 1. (Gupta 2004) The Fertile Crescent (yellow, in center) along with South and central Asia are regions that fostered the earliest use of agriculture and domestication of plants and animals.

The warm conditions between the end of the last glacial maximum and the start of the Holocene were interrupted by the Younger Dryas, a brief cold period starting 11, 000 BP. (Fig. 2). Many people returned to hunting and gathering, or located to ecologically choice areas. It is during the Younger Dryas that the use of agriculture first became prominent. This is explained by the "oasis" theory of V. Gordon Childe in that large regional populations relocated to the geographic areas that had water available (1951: 6772; cited by Dow, et al., 2005). These were also the best food production sites, and people learned agricultural practices from those that knew how. The close proximity of people, plants, and animals was ideal for domestication, and spread of knowledge. Bar- 
Yosef and Richard Meadow ${ }^{1}$ argue that the cold, dry climate of the Younger Dryas may have caused yields of wild cereals to decrease, thereby increasing the need for cultivation (Dow, et al., 2005).

If the farming technology had remained constant and the colder climate longer, society would have crossed a population threshold that would have forced a return to foraging as a lifestyle. However, two things happened; the domestication of plants and animals increased productivity and the Younger Dryas ended abruptly at 10,000 B.P. The onset of warm and wet climate conditions allowed the population to grow and expand once again. These people took with them domesticated plants and animals, along with knowledge of advanced agricultural practices, and sedentary agriculture became widespread.

\section{The Indian Subcontinent}

The Indian Subcontinent was an early center for plant and animal domestication because of the favorable climate. Here the South Asian/Indian Ocean monsoon climate affected the daily life of the people. The seasonal and decadal changes associated with the monsoon allowed many different types of vegetation to grow. The paleomonsoon records show that the monsoon was intensified in the early Holocene, indicating a much warmer and wet climate than present (Pandey, et al., 2003). The increased winter moisture of the early Holocene allowed the people to grow winter crops of wheat and barley. People developed a very close relationship with domesticated plants and animals. They had wild animals as pets and worshiped sacred trees, the Pipal and Barh (banyan). Their deep respect for and intrigue with this abundant nature caused them to research the medicinal properties of plants, resulting in the medicinal science called Ayurveda. Agriculture allowed people to establish permanent settlements and elaborate societies. People developed the first irrigation systems as a result of the variability of the monsoon seasons; the summer monsoon was longer than the winter monsoon, so they may have collected rainwater to assist the winter crops (Pandey, et al., 2003). The late Holocene (the last 4000 years) was drier and led to diversification of crops (Gupta, 2004).

The Middle Yangtze River Valley

In the Middle Yangtze River Valley of China, evidence of domesticated rice was found in fossil rice phytoliths identified from the late glacial to Holocene time frame $(13,900 \mathrm{BP}-$ $10,000 \mathrm{BP})$. Domesticated rice phytoliths disappeared during the last glaciation, the Younger Dryas (13,000-10,000 BP). This suggests the climate had a large effect on culture because people stopped farming when the conditions became colder, but resumed farming with the onset of warmer and wetter conditions after 10,000 BP.

\section{The Medieval Warm Period and the Little Ice Age}

The Medieval Warm Period was a time of unusual warmth across Europe that lasted from 800 to $1300 \mathrm{CE}$ and ended with the onset of the Little Ice Age $(1350-1850 \mathrm{CE})$. The

1 Bar-Yosef, O., and R. Meadow, 1995. The origins of agriculture in the near east, Ch. 3 in T. Douglas Price and Anne Birgitte

Gebauer, eds., Last Hunters, First Farmers: New Perspectives on the Prehistoric Transition to Agriculture, School of American 
Norse, under Eric the Red, colonized south Greenland in CE 985 because of the mild climate and stable ocean conditions (Sherwood and Idso, 2004). The arrival of the Norse occurred at the same time as the peak of medieval warming recorded in the GISP2 ice core from the summit region of central Greenland (Fig.2). This suggests the Norse took advantage of the peak medieval warm climate to establish settlements on the coast of Greenland. The demise of the Norse, after five centuries, may be attributed to onset of the Little Ice Age. The increased winter sea-ice closed off trade routes with mainland Europe during the late 14th century, which the Norse settlements relied upon (Mann, 2001). The collapse of Norse colonies involves many different complex sociological factors but the Little Ice Age may have been a determining factor.



Figure 2 (Alley, 2000). The Younger Dryas is shown in this graph from the GISP2 ice core of Greenland at 11,500 BP. The peak Medieval Warm Period is shown at $985 \mathrm{CE}$, and the Little Ice Age at $1350 \mathrm{CE}$.

The Little Ice Age refers to the cold period that punctuated 16th—mid 19th century European climate- and culture. This period of modest cooling began when mountain glaciers expanded across Europe following the medieval warm period and ended with a retreat of these glaciers in the 20th century. Mountain glacier retreats and advances are illustrated in paintings of mountain glaciers in the French and Swiss Alps and recorded in detailed thermometer measurements.

The glacial advances of the Little Ice Age affected nearby human populations both positively and negatively. In the Chamonix Valley, near Mont Blanc, France, farms and villages were lost to an advancing mountain glacier. Villagers summoned the bishop to perform an exorcism -believing that something evil was the cause. This procedure was not successful. In northern Europe colder weather combined with changes in atmospheric 
circulation and caused the crops to fail. Famine, disease, and increased child mortality in the $17^{\text {th }}$ to $19^{\text {th }}$ century were related to the colder conditions. However, In London the annual winter freezing of the Thames River was celebrated, and the colder climate inspired writers and painters. Charles Dickens wrote about the beautiful white Christmas, and Marry Shelly wrote "Frankenstein's Monster" while snowed in.

\section{Cultural Responses to Drought}

Water abundance is more important than temperature for plants and animals to survive in arid and semi-arid climates (de Monocal, 2001). One of the most recent droughts that had a heavy impact on society is the Dust Bowl drought of the 1930's. This lasted less than six years, from 1933-38, and was one the most devastating ecological, sociological, agricultural, and economic disasters in U.S. history. This drought was caused by a lack of precipitation across the northern Great Plains. It displaced millions of people and is attributed to one cause of the subsequent economic collapse. This climatic event was made worse by poor agricultural practices, including overcapitalization of crops in a time of abundant rainfall just prior to the drought (NDMC, 2006). In the 1920's, the high cost of machinery and the low pay for crops meant farmers had to cultivate more land in order to pay their debts. This meant farming less than ideal areas, and resulted in soil erosion and nutrient leaching. Therefore, cultivating these areas increased the occurrence of crop failures and increased the regions vulnerability to drought. In the 1950's a similar decadal drought occurred in the American Southwest, but its effects were much less severe because of improved agricultural practices and the implementation of disaster relief programs (de Monocal, 2001).

Tree ring chronology from northeastern Virginia show drought periods from 1587AD to 1589 and 1606 - 1612 were the driest in the last 700 years (de Monocal). In August 1587 English colonists settled in Roanoke Virginia, but had vanished by the time re- supply ships arrived four years later. They became known as "the lost tribe," their fate originally attributed to poor planning and inadequate supplies. Based on the tree ring data, it is now believed they were the victims of severe drought that began at the time of their arrival. In April 1607, a larger colony settled in Jamestown Virginia, at the time of extreme drought. $80 \%$ of the population died by 1632 from malnutrition associated with the arid climate.

The "Great Drought" of the 1280's occurred in the American Southwest, lasting 26 years (de Monocal). This was a prolonged and widespread event, but less severe than the 1580's drought. The Anasazi, ancestors of the modern Pueblo Indians, lived in established villages in the semi-arid highlands and canyons. Near the end of the $13^{\text {th }}$ century many villages were hastily abandoned, according to archaeological findings. Sociological factors, including political division and warfare, may have played a role in the collapse of Anasazi civilization; however drought could have been the determining factor (fig. 3). 




Figure 3. (De Monocal, 2001) Drought history of southwestern America from 1200 CE to 1994 CE reconstructed from tree rings. Black curves represent decades, grey curves are annual records. (A) Time series. (B) The Dust Bowl drought of the 1930's peaked in 1934 and the 1950's drought peaked in 1956. (C) The 1580's drought peaked in 1583. (D) The 1280's Drought peaked in 1280. Short intense droughts such as the Dust Bowl recurred once or twice per century and multidecadal droughts occur a few times in a millennium.

The Akkadian empire (4200 to 4170 BP)

The Akkadian empire of Mesopotamia, ruled by Sargon of Akkad, was established 4300 BP from the Tigris-Euphrates Rivers to the Persian Gulf. This highly productive agrarian society collapsed after less than 100 years most likely because of a climate shift to more arid conditions. Archeological evidence shows the populace abandoned northern Mesopotamian agricultural plains and moved to the south, where population numbers expanded. This prompted the south to construct the "Repeller of Amorites", a $180 \mathrm{~km}$ wall, to be built across Mesopotamia in an effort to stop the migration. Archaeological evidence shows the Akkadian civilization collapsed in spite of the fact that they had highly developed water regulation technologies and had implemented grain storage in an effort to mitigate the effects of variable precipitation.

Evidence of this regional drought is found in marine sediment cores from the Gulf of Omen which contains wind born sediments from the Mesopotamian sources (de Monocal 2001 citing Cullen, et al., 2000). An abrupt increase in eolian dust from 4025 $\mathrm{BP}$ reveals that arid conditions persisted in the region for 300 years. A comparison of 
geochemical ash shards found at the archeological site and in the marine sediment record reveal that an abrupt climate shift to arid conditions occurred at the same time as the collapse of the Akkadian empire, further implicating climate change as the cause (Fig. 4).

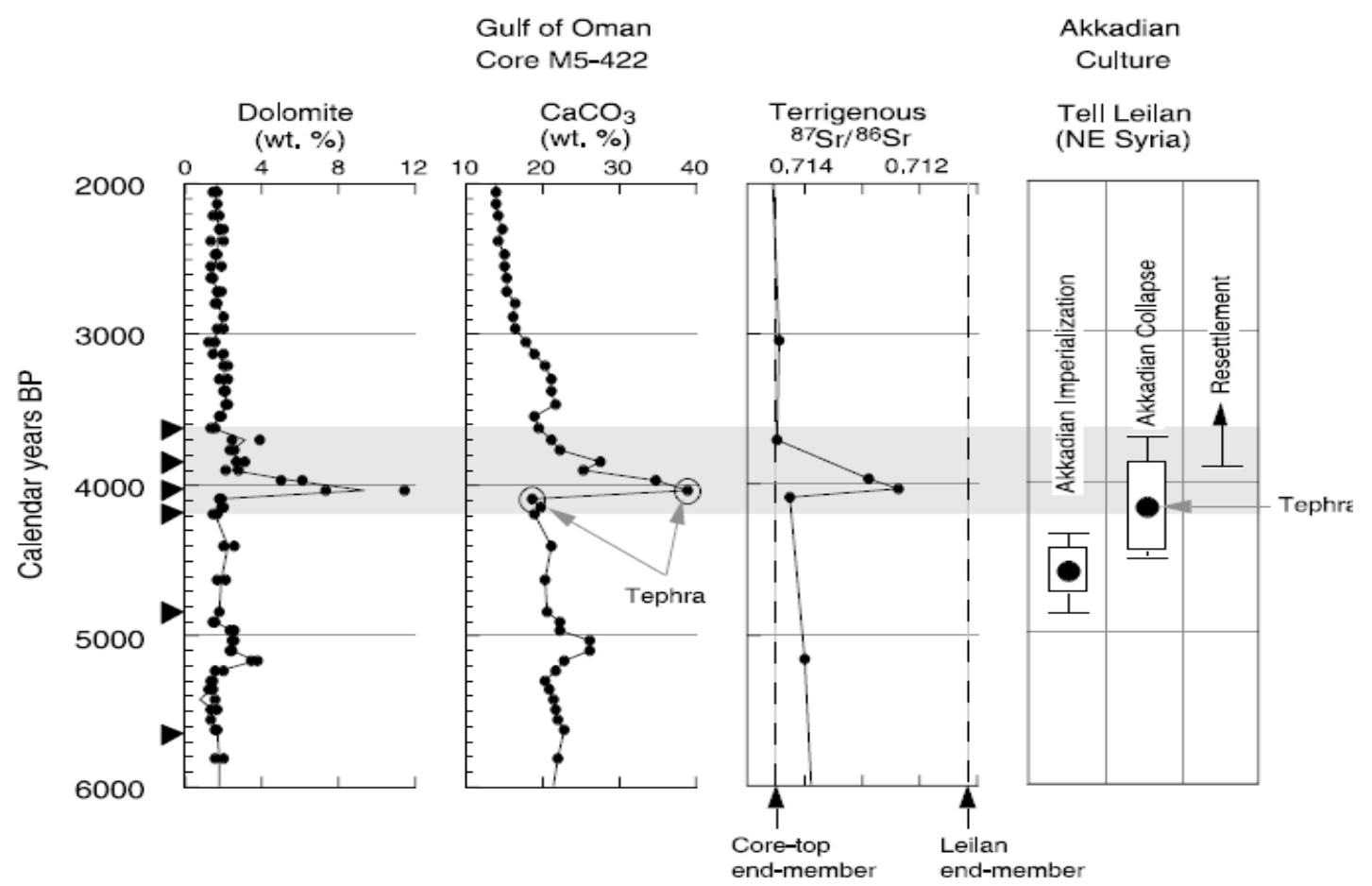

Figure 4 (de Monocal, 2001). Collapse of the Akkadian empire occurred at 4170, as documented by detailed radiocarbon dates from archaeological sites. Windborne sediments and deep-sea sediment cores from the Gulf of Oman (down wind from eolian dust source areas of Mesopotamian sites) are used to reconstruct aridity. The increase of eolian dolomite and calcite ate 4025 BP reveals a 300 year drought.

The Classic Maya (250 to 850 CE)

The arid conditions of the Peruvian coast have required the populace to rely on elaborate irrigation systems to support agriculture for thousands of years. These Pre-Columbian civilizations provide excellent insight into past links between climate variability and cultural change because they were densely populated, highly sophisticated agrian societies that lived in a challenging environment (de Monocal).

The Classic Mayans ruled Mesoamerica from $250 \mathrm{CE}$ to $850 \mathrm{CE}$, densely populating the southern lowlands of the Yucatan peninsula. Precipitation ranged from 500 to 4000 millimeters from north to south and a pronounced winter dry season runs from January to May. This is due to a seasonal migration of moisture known as the "Meteorological equator". The Mayans adapted to the lack of surface water with large scale water-collection systems. Their cities were designed to catch rainfall and channel it into quarries, excavations, and natural depressions. They placed reservoirs at the tops of hills, using gravity to irrigate land below. Ultimately, they depended on seasonal rains for survival (Peterson and Gerald H. Haug, 2005).

Sediment core measurements from Yucatan Lakes and the Cariaco basin of northern Venezuela indicate the driest interval of the last 7,000 years fell between 800 
and 1,000 CE. (1300- 1100 BP), the same time as the Mayan collapse (Fig.5). The Mayan collapse occurred first in the southern and central Yucatan low lands and in the northern lowlands a century or more later. This is contradictory to rain patterns because the northern lowlands generally get less rainfall than the southern, but other factors must be considered. There is a natural underground aquifer where the Mayans built their civilization. This aquifer was more accessible from the northern lowlands. While southern villages got more rainfall, northern settlements were more dependent on the aquifer rather than rain, and would have been more resistant to drought. Richardson B.Gill $^{2}$ argues for three phases of drought-related collapse between 760 and $910 \mathrm{CE}$, with distinct regional progression (Peterson and Haug, 2005). The first phase was marked by the societal collapse of the western lowlands, where there was very little accessible groundwater. The second phase was restricted to the southeastern portion of the lowlands, where freshwater lagoons may have provided water until that point. The final phase of the drought affected central and northern lowlands. These regions were most affected during the drought from 800 to $1000 \mathrm{CE}$ (de Monocal).

Archeological excavations show that Mayan population decreased from $\sim 200$ persons $/ \mathrm{km} 2$ at the peak classic period to less than 100 persons $/ \mathrm{km} 2$ by ca $900 \mathrm{CE}$. By $1500 \mathrm{CE}$, many watersheds had been completely abandoned, and the total collapse of Mayan civilization is marked around $800 \mathrm{CE}$. The Evidence points to a megadrought leading to the demise of the Mayans. Many other factors contributed, including overpopulation and political turmoil, but the drought may have triggered a series of events destabilizing Mayan society.



Figure 5 (Peterson and Haug, 2005). Sediment cores from the Cariaco Basin show four severe droughts within spans of 50 years were inflicted on the Maya between 760 and 910 CE.

The Mochica Polity (300 to 500 CE)

The Mochica Polity ruled the entire northern Peruvian coastline of the Sechura desert from ca 300 to $500 \mathrm{CE}$ (de Monocal). This is known as the early Moche IV period, when people lived in elaborate urban centers with monumental adobe brick structures. The capital site of Moche contains the largest adobe structure in the world, the Huaca del Sol.

2 Gill, R. 2000. The Great Maya Droughts: Water, Life, and Death. Albuquerque: University of New Mexico Press 
This large cultural center was very abruptly abandoned at 600CE. Archaeological evidence reveals that large sand dunes overran the main irrigation channels at the time of abandonment. The subsequent Moche $\mathrm{V}$ culture relocated farther inland near the Highland River between 600 and $750 \mathrm{CE}$. This transition occurred at a speed and scope unprecedented for this region.

Resolution records from the Quelccaya ice core (Peru) indicate that an abrupt climate change is the underlying factor for the Mache IV-Mache V transition (Fig.6, de Monocal). Variations in oxygen isotopes, accumulation rate, and insoluble particle concentration over the last 1500 years contain evidence of large climate changes in this region. This data shows less ice accumulation between 563 and $594 \mathrm{CE}$. Comparing this paleoclimatic data with cultural records show that 60 years of increased winds along with 30 years of drought occurred just prior to the cultural transition. The loss of coastal irrigation channels from encroaching sand dunes were due to an abrupt shift in climate toward more arid conditions, and explain the transition of Mache culture to highland valleys with more water. Regional ice core accumulations from the first and second millennium CE reveal that this cultural transition from highland to lowland areas has occurred repeatedly with corresponding periods of drought, resulting in the rise and fall of agrian cultures in both Peru and Ecuador (de Monocal).

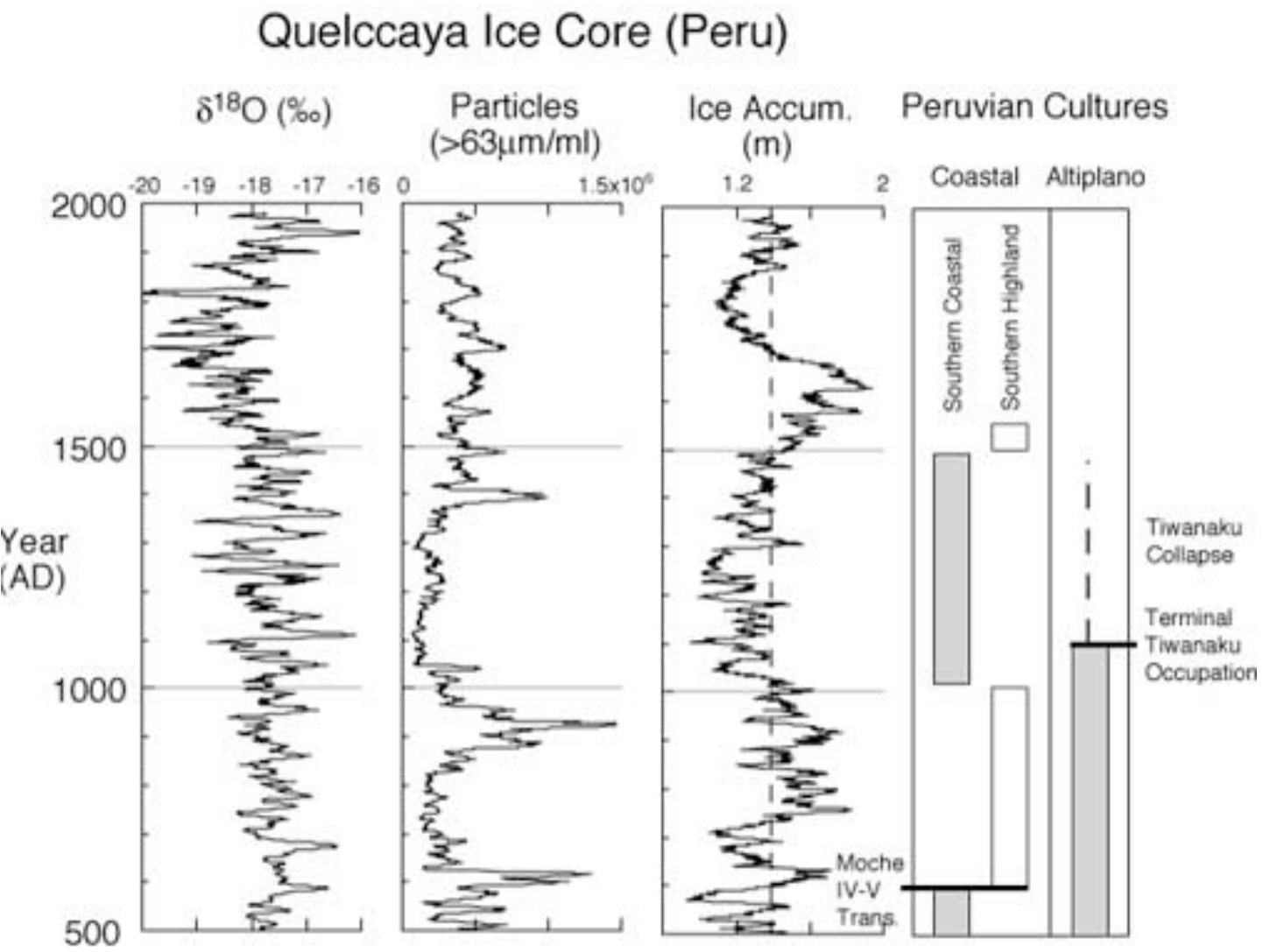

Figure 6 (de Monocal, 2001). The Quelccaya ice core taken near Lake Titicaca shows multicentury shifts in precipitation spanning the last 1500 years. Coinciding with drought, the Mochica abandoned coastal urban centers and moved to locations with a better water supply between 600-750 A.D. The Tiwanaku abandoned urban centers and cultivation fields the same time as severe drought at $1100 \mathrm{CE}$. 
The Tiwanaku culture (300 B.C. to 1100 CE.)

The Tiwanaku culture consisted of urban and rural areas that surrounded Lake Titicaca in southern Bolivian-peruvian altiplano at an elevation of 4000 meters. Their rich agricultural system thrived for 1500 years from $300 \mathrm{BP}$. to $1100 \mathrm{CE}$. They used innovative agricultural techniques such as raised field cultivation to promote nutrient recycling, and irrigation canals that protect the crops from freezing. This agricultural system sustained half a million people, including the densely populated urban center and rural outlying areas. The urban center and raised fields were abandoned abruptly around $1100 \mathrm{CE}$, with the full collapse of civilization occurring over the $12^{\text {th }}$ to $15^{\text {th }}$ centuries.

The Queleccaya ice core was drilled in close proximity to Lake Titicaca and provides paleoclimatical data that can be compared with the collapse of the Tiwanaku civilization. The Quelccaya ice and oxygen isotope accumulation reveal that a lower ice accumulation rate occurred at the same time as the cultural shift (Fig.6). Dry conditions started after $1040 \mathrm{CE}$. and persisted in the area for several centuries. Sediment cores from lake Titicaca reveal that the water level dropped 10 meters at this time. The Tiwanaku cultural changes occurred after an abrupt and persistent, hot and dry climate impacted the raised field agriculture system in such a way that it could not sustain the population.

\section{Mechanisms for climate change}

The relatively recent climatical events such as the Dust Bowl drought of the 1930's, the drought of 1950's American southwest, the drought affecting English settlers of northern Virginia in the late 16th and early $17^{\text {th }}$ centuries, and the Great Drought of the 1280's persisted for a few decades to a few years. Complex societies can adapt to these climate fluctuations, however more persistent events have different challenges and require different coping strategies. Multidecadal to Multicentury climate change punctuated the Holocene epoch as part of natural climate variability. The transition into, and out of these events can be very sudden, sometimes occurring in less than ten years. The Holocene was once thought to be a relatively stable warm period, but detailed paleoclimate records illustrate that several multicentury and widespread cooling events recurred about every 1500 years, these pronounced climate variations are linked with changes in the subpolar and subtropical ocean currents as well as changes on terrestrial climates (de Monocal).

These events occurred concurrently across the North Atlantic. Thermohaline circulation (the triplex of wind, heat, and salinity driving ocean circulation that effects global climate) and ocean atmosphere coupling (a complex system of heat transfer that causes climate variability) are the most likely causes for these climate shifts (de Monocal). These systems govern the modern climate stability and occur over long periods of time. The Little Ice Age (1300 to $1870 \mathrm{CE})$ and the preceding medieval warm period ( 800 to $1300 \mathrm{CE}$ ) represent the most recent millennial style Holocene climate cycle. Analysis from these events show that the primary factors affecting global climate variations over the last millennium were variations in solar irradiance and the affects from active volcanoes, together counting for half the temperature variance. An anthropogenic increase in atmospheric green house gases must be considered as an 
additional forcing agent when accounting for $20^{\text {th }}$ century warmth in climate models. Over the last millennium there has been a strong correlation between variant solar irradiance, sea surface temperature, and drought. This is evidence that solar variability has a large influence on global climate on multdecadal to multicentury time scales.

\section{Conclusion}

The development of agriculture, along with the domestication of plants and animals is due to sudden shifts between extreme cold, dry conditions, and a warm, wet climate. Agriculture is responsible for allowing the large populations we have now. Without agriculture society could not have expanded. It allowed people stay in one area, establish villages, and develop communities. Population increases and technical advances may have played a role in the origin of agriculture, but the climatical shift to warm tropical conditions at the end of the last glacial maximum along with the subsequent cooling and warming of the Younger Dryas can be attributed as one major cause of widespread agriculture and the establishment of sedentary societies.

The Little Ice Age and the Medieval Warm Period were millennium scale events that occurred relatively recently. The impact on society is well documented. Many societies adapted and thrived during this time, celebrating the long winters, while other societies suffered from famine and mortality associated with the colder climate. The late Holocene droughts that caused extreme cultural responses were much more severe in duration and intensity than anything that has ever been recorded during the modern instrumental period. Natural variability of drought can be categorized as interannual, decadal, and mutidecadal to multicentury. Detailed paleoclimatic records show the severity and relevance of rare multidecadal to multicentury droughts. The data shows that abrupt, intense, and persistent droughts occurred at the same time as societal collapse of the Akkadian, Maya, Mochica, and Tiwawanaku. This illustrates that in times of environmental stress, a society can lower subsistence levels by reorganizing supply and production systems.

These ancient events are relevant to modern times in that they illustrate both the resilience and vulnerability of large complex civilizations to climate change. Complex societies are not completely powerless nor fully adaptive to climate variability (de Monocal). Ancient civilizations, as with many modern cultures, adapted and thrived in marginal climate conditions with large interannual climate variability. As with modern society, ancient cultures gauged their ability to adapt to future climate conditions using historical records of climate change. What is different is that these ancient cultures actually witnessed multidecadal and multicentury drought, while modern society has not. Cultural responses to extreme and sudden climate change provide insight into the vulnerability of modern society, and the importance of preparedness for the future. 


\section{References}

Alley, R., 2000. The Younger Dryas cold interval as viewed from central Greenland. Quaternary Science Reviews 19, 213-226.

Alley, R., Marotzke, J., Nordhaus, W., Overpeck, J., Peteet, D., Pielke R. Jr., Pierrehumbert, R., Rhines, P., Stocker,T., Talley, L., and J. Wallace. 2003. Abrupt climate change. Science 299, 2005-2009.

Bar-Yosef, O., and R. Meadow, 1995. The origins of agriculture in the near east, Ch. 3 in T. Douglas Price and Anne Birgitte Gebauer, eds., Last Hunters, First Farmers: New Perspectives on the Prehistoric Transition to Agriculture, School of American Research Press, Santa Fe, New Mexico, 39-94.

De Monocal, P., 2001. Cultural responses to climate change during the late Holocene. Science 292, 667-673.

Dow, G., Olewiler, N., and C. Reed, 2005. The transition to agriculture: Climate reversals, population density, and technical change, Economic History 0509003, EconWPA.

Gill, R. 2000. The Great Maya Droughts: Water, Life, and Death. Albuquerque: University of New Mexico Press.

Gupta, A., 2004. Origin of agriculture and domestication of plants and animals linked to early Holocene climate amelioration. Current Science 87, 54-59.

Kalis, A., Merkt, J., and J. Wunderlich. 2002. Environmental changes during the Holocene climatic optimum in central Europe - human impact and natural causes. Quaternary Science Reviews 22, 33-79.

Mann, M.E. 2001. Little ice age. In Encyclopedia of Global Environmental Change, ed. M.C. MacCracken and J.S. Perry. London: John Wiley and Sons Ltd.

National Drought Mitigation Center (NDMC). 2006. Downloaded from http://drought.unl.edu/whatis/dustbowl.htm

Pandey, D., Gupta, A. and Anderson, D. 2003. Rainwater harvesting as an adaptation to climate change. Current Science 85, 46-59.

Peterson, L.; and G. Haug. 2005. Climate and the collapse of Maya Civilization. American Scientist 93, 322-329.

Richerson, P., Boyd, R., and Bettinger, R. 2001, Was agriculture impossible during the Pleistocene but mandatory during the Holocene? A climate change hypothesis. American Antiquity 66, 387-411.

Sherwood, K. and C. Idso., 2004. The establishment and demise of the medieval Nordic settlements on Greenland: The role of natural climate change. Co2 Science 7, 22. 